\title{
Hindrance Stressors, Career Plateau, Work-Related Depression and Emotional Exhaustion among Flight Attendants
}

\author{
Homayoun Pasha SAFAVI iD a Mona BOUZARI iD b Taraneh FOROUTAN iD c \\ a Cyprus International University, Faculty of Economics and Administrative Sciences, Department of Business Administration, Turkish \\ Republic of Northern Cyprus, Turkey hpsafavi@ciu.edu.tr \\ b European University of Lefke, School of Tourism \& Hotel Management, Turkish Republic of Northern Cyprus, Turkey \\ mbouzari@eul.edu.tr \\ c Final International University, Faculty of Economics and Administrative Sciences, Turkish Republic of Northern Cyprus, Turkey \\ taraneh.foroutan@final.edu.tr
}

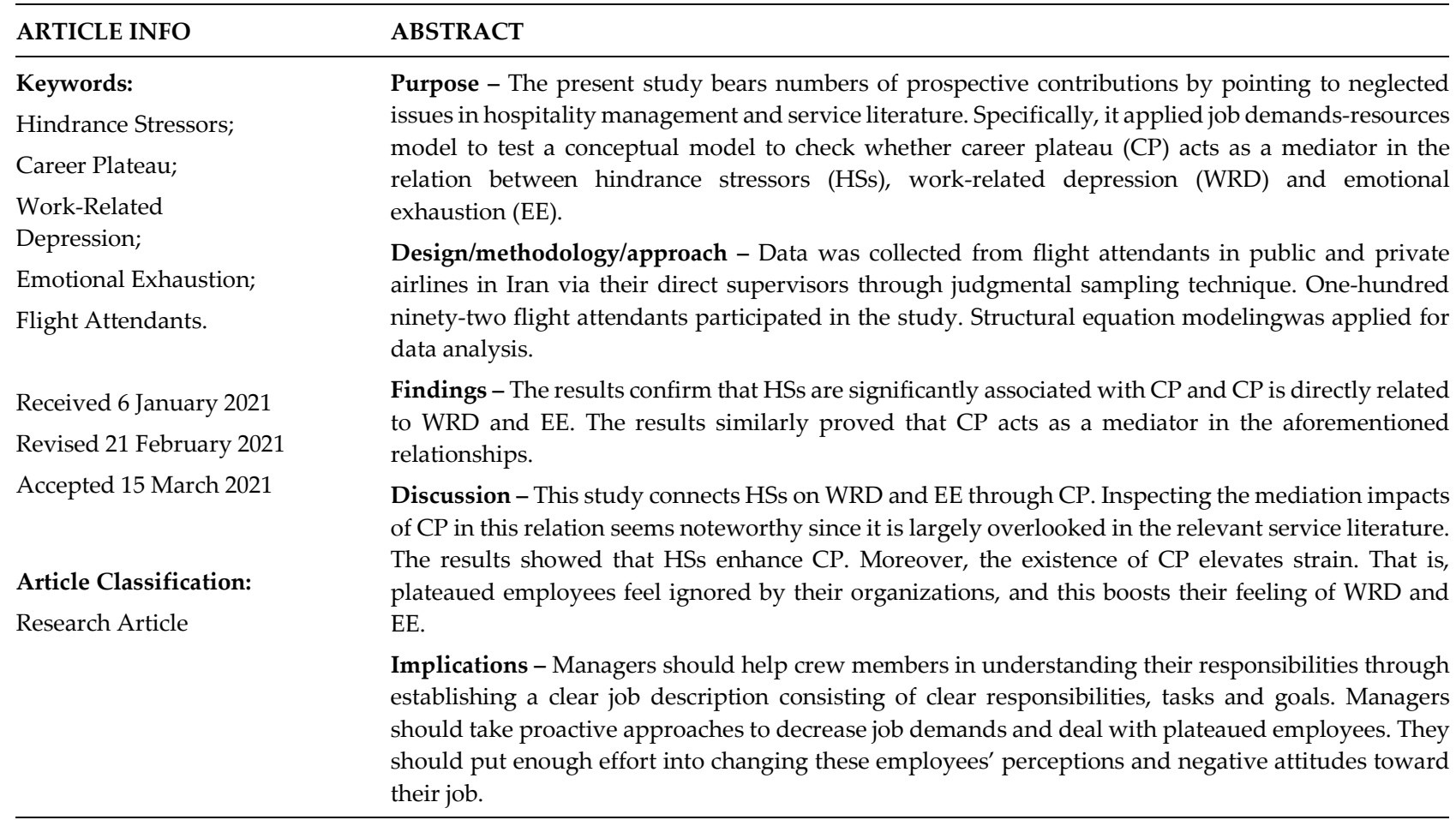

\section{INTRODUCTION}

Mental health is a central concern for workplace accomplishment. Two common and widespread mental health problems in the work environment are WRD and EE (Karatepe and Ehsani, 2012; Alola et al., 2019). Depression signifies "prolonged negative feelings, inability to concentrate or function normally and other related depressive symptomatology" (Baba et al., 1999: 166); whereas EE refers to "feelings of being overextended and depleted of one's emotional and physical resources" (Maslach and Leiter, 2008) which is damaging for both individuals and organizations (Rathi and Lee, 2016). As reported by the Office of Applied Studies (2007), US companies annually lose around \$30-\$44 billion caused by employee depression through diminished productivity and personnel absenteeism. Depression grants horrendous news for the hospitality staff (Karatepe and Ehsani, 2012), and flight attendants are no exception. Flight attendants are under continuous stress which makes them susceptible to depressing mood responses (Sonnentag and Natter, 2004). Due to the nature of their workplace, flight attendants would experience psychological health (Chang and JuMei, 2009). Work-related stress needs to be managed because an increasing number of studies show that stress

\section{Suggested Citation}

Safavi, H. P., Bouzari, M., Foroutan, T. (2021). Hindrance Stressors, Career Plateau, Work-Related Depression And Emotional Exhaustion Among Flight Attendants, Journal of Business Research-Turk, 13 (1), 83-99. 


\section{H. P. Safavi - M. Bouzari - T. Foroutan 13/1 (2021) 83-99}

has a direct impact on psychological health (O'neill and Davis, 2011) specifically in the case of flight attendants (Ko, 2018). Flight attendants are commonly affected by jetlag, dim flight, and work overload (Ballard et al., 2006) which exposure them to common mental disorders (CMDs) including depressive symptoms, anxiety, difficulty in concentrating, fatigue, and irritability (Feijo et al., 2014). Uncertain work hours, night-shift duties and time-zone changes are among the main problems faced by them (Chen, 2017). Specifically, due to recurrent and extended contacts with customers and obeying the organizations' expectations, they develop frequent EE (Chang and Ju-Mei, 2009). Consequently, because of the above-mentioned noticeable cost and in congruence with recognized undesirable results from depression and EE (Alola et al., 2019; Chen and Kao, 2011; Lv et al., 2012), it appears to be pivotal to review and assess the factors that potentially worsen such negative feelings among cabin crews. Yet, unexpectedly, this topic has been ignored.

One probable source of the aforesaid detrimental feelings among cabin crews could emerge from experiencing the point and stage in a career with the less possibility and prospect of additional promotion known as $\mathrm{CP}$ (Ference et al., 1977). Two unanimous categorizations of CP, namely hierarchical plateau and job content plateau have received remarkable attention since its emergence around 40 years ago (Yang et al., 2018). Hierarchical plateau denotes a dearth of promotion in an organization whereas job content plateau implies a lateral stagnation by which individuals sense that their job is not challenging due to monotonous job responsibilities (Bardwick, 1986; Feldman and Weitz, 1988). Plateaued individuals commonly report unfavorable and undesirable work outcomes such as poor satisfaction and well-being, poorer job performance and organizational commitment, and a higher level of intentions to quit jobs (Salami, 2010; Wickramasinghe and Jayaweera, 2010; Yang et al.,2018).

In addition, work-related stress is extremely related with an increased risk of numerous psychiatric disorders (e.g. depression) among staffs (Choi and Kang, 2010; Lee et al., 2013). With this conception, it seems that the main potential cause of the stated destructive feelings among flight attendants could arise from stressful job demands known as HSs. HSs are considered as a distinct type of stressors related to the umbrella concept of work-related stress (Cavanaugh et al., 2000) which refers to job demands, reflected as hindering growth concerning personal attainments or goal fulfillment (Cavanaugh et al., 2000). HSs are the cause of extreme or unsolicited burden and frustration, discomforting efforts to grow and achieve work-related goals (French et al., 2019). Examples of HSs consist of RA and RC (Crawford et al., 2010). RA and RC have been identified to represent flight attendants' work-related HSs in numerous studies (Lee and Kim, 2018; Öge et al., 2018; Alam, 2016; Karatepe and Choubtarash, 2014; Jou et al., 2013; Tourigny et al., 2010). Despite the existence of evidence regarding the impacts of the two mentioned work-related stressors, conferring to a recent inquiry conducted by Karatepe and Kim (2020), the topic deserves more attention and investigation, precisely with the focal focus on flight attendants (Ko, 2018).

\subsection{Purpose and Contribution of the study}

Grounded in this background, the current investigation offers and tests a conceptual model of whether CP mediates the effects of HSs on WRD and EE. More specifically, conferring to job demands-resources (JD-R) model (Bakker and Demerouti, 2007), data collected from cabin crews in Iran is applied to assess (a) the effect of HSs on CP; (b) the effect of CP on WRD and EE and (c) the mediating role of CP in the relation between HSs and the aforesaid outcomes.

The present study bears numbers of prospective contributions by pointing to neglected issues in hospitality management and service literature. Firstly, there is a recent call for more research to inspect the factors that aggravate and intensify WRD and EE in organizations (Alola et al., 2019; Chen et al., 2019; Vandevala et al., 2017). In fact, it is justified that job-related stress is associated with EE and WRD (Zhong et al., 2009). Even though, the mechanism that contributes to the increased risk for these psychiatric problems with high levels of work-related stress is still arguable (Lee et al., 2013). With this realization, this study takes into consideration the effect of HSs on the aforesaid mental health problems and the mechanism through which these demands lead to EE and WRD in the workplace. What is more, while it is commonly acknowledged that CP has a detrimental effect on individuals and organizations (Heilmann, et al., 2008; Lapalme et al., 2009; Lin et al., 2018; Shabeer et al., 2019; Yang et al., 2019) an apparent picture of precursors that effect plateauing is missing in the present literature (Shabeer et al., 2019). This inquiry responds to the existing voids by testing job demands as a probable influential factor related to CP. Addedly, a close examination of the related literature 


\section{H. P. Safavi - M. Bouzari - T. Foroutan 13/1 (2021) 83-99}

reveals that inspecting factors affecting $\mathrm{CP}$ and its consequences is largely overlooked in developing countries in Middle East regions. Iran seems to provide an exclusive setting to inspect the study relations. The country is trying to decrease reliance on limited oil reserves through the tourism and hospitality industry, however, this industry is in the progress stage (Karatepe and Shahriari, 2014). More specifically, there are several severe problems such as poor marketing and lack of HR practices such as training, staff selection and recruitment (Morakabati, 2011; Zamani-Farahani and Henderson, 2010). Iran is unexpectedly underrepresented in the current and available service literature (Shahin and Dabestani, 2010). Specifically, in the airline industry, flight attendants in Iran are overwhelmed with job stressors and work in a setting with insufficient required human resource practices (Vatankhah et al., 2017). Notably, there is no indication of viable statistics or study towards the loss and harms incurred by facing mental health problems among these staff in Iran. Given the fact that the mentioned health issues harm both employees and companies, it is imperative to address this void, so that proper interferences can be undertaken to avert facing or at least decreasing aforesaid mental problems among cabin crews in Iran.

\section{LITERATURE REVIEW}

\subsection{Hindrance stressors and career plateau}

Psychosocial stressors are a universal phenomenon and a serious aspect of the work environment and received vast attention in the literature (Lazarus, 1993). Numerous investigations anticipated that stressors alter employee behaviors and attitudes (Jex and Crossley, 2005, Cynkar, 2007). For instance, conducting a metaanalysis, Lee and Ashforth (1996) found role stressors to be one of the most important antecedents of burnout variables and EE. Stressors have also been found to affect employees' well-being (Tsaur and Tang, 2012; FortesFerreira et al., 2006; Bowen et al., 2014), work engagement (Montgomery et al., 2015), organizational citizenship behavior, commitment (Lambert et al., 2012) and job satisfaction (Podsakoff et al., 2007). Literature also reveals evidence of relationships between work stressors and counterproductive workplace behaviors (Kuhn, 1988), workplace accidents (Steffy et al., 1986).

Work-related stressors fall into two classifications (challenge stressors and HSs). Challenge stressors are incentives such as great levels of responsibility and workload. HSs, on the other hand, are stimuli such as RA and RC (Cavanaugh et al., 2000). HSs include stressful demands which are usually out of employees contrl and therefore they may prevent the opportunity for personal growth, goal achievement, and learning (LePine et al., 2005; Tims et al., 2013). They can generally be the source of negative feelings of anxiety and nervousness which consequently lead to further emotion-focused coping strategies such as distraction, revenge, and withdrawal (Wallace et al., 2009). HSs reduce creativity (Geng et al., 2014), organizational commitment, job satisfaction (Podsakoff et al. 2007; Webster et al., 2011), work engagement (Ozer et al., 2014). Moreover, they boost stress (Rodell and Judge, 2009) and intention to leave among employees (Webster et al., 2011, Babakus et al., 2017),

RA refers to unclear and vague expectancies for employees that happen when they face uncertain circumstances and unaware of what is expected from them. Additionally, RC is described as concurrent opposing expectations from managers, coworkers, and customers which make completion of the required tasks more difficult (Katz and Kahn, 1978). Reviewing the literature revealed that any kind of RC and/ or RA can lead to higher depression, tension, anxiety, and EE (Fried et al., 2008; Ortqvist and Wincent, 2006). They similarly diminish service quality, organizational commitment (Lin and Ling, 2018), and job satisfaction (Arnold et al., 1998)

Firstly, presented around 40 years ago, $\mathrm{CP}$ refers to a stage where the prospect of acquiring future promotion is limit and implausible (Ference et al., 1977). According to literature, the plateau field has concentrated on two categories of plateau; known as hierarchical and job content plateaus. Hierarchical plateau demonstrates the lack of promotion in an organization. Moreover, job content plateau refers to lateral inertia in which employees sense that their job is undemanding or they don't receive additional work responsibilities (Bardwick, 1986).

As argued by Beheshtifar and Modaber, (2013), there is a direct significant connection between job-related stress and $\mathrm{CP}$ variables. HSs impede future achievements and personal growth and therefore demotivate employees (Fong et al., 2018). Employees confronting HSs presume that there is no positive connotation 


\section{H. P. Safavi - M. Bouzari - T. Foroutan 13/1 (2021) 83-99}

between their efforts and surviving. They also believe they have no control over these stressors and no level of effort will help them to successfully surpass this stressor (Wallace et al., 2009). These employees even when performing well in their existing jobs, will remark a little room for growth or accomplishment in the future (Fong et al., 2018) which can lead to CP. Hence, the more employees opposed to HSs, the more they are likely to experience $\mathrm{CP}$.

To extend over the work of prior and recent research, the current study employs the job demand resource model (JD-R) which is commonly considered in the work-related stress research model (Bakker and Demerouti, 2007). Conferring to JD-R, work environments can be separated into two different groups of job demands and job resources. Job demands conceivably lead to the strain that necessitates continuous physical or psychological efforts (e.g., cognitive or emotional). Therefore, they are allied with probable costs for these efforts. In contrast, job resources represent the societal, psychological, physical, and organizational aspects of the job. These features inspire personal growth, advancement, and accomplishing work-related goals which help in reducing job demands (Bakker and Demerouti, 2007).

Rendering to the JD-R model, two diverse procedures are presumed when considering the relationship between stressors and work-related outcomes (Bakker and Demerouti, 2007). The health impairment process suggests that excessive job strains or unwell designed occupations might deplete employees' emotional and physical resources, thus, lead to negative health and job outcomes. However, the motivational process suggests that the existence of job resources diminishes job demands and boosts employees' progression and development (Bakker and Demerouti, 2007; Llorens et al., 2006).

Based on tenants of the JD-R model, job demands (e.g., RC and RA) lead to the feeling of strain and stress (Demerouti et al., 2001; Lee and Ashforth, 1996), and suppress employees' future growth and development which eventually lead to higher CP. Therefore, employees facing HSs are more probable to view such stressors as a possible threat to their individual progress and in so doing increasing perception of CP. Accordingly, we propose:

H1: HSs, as manifested by $R A$ and $R C$, are significantly related to $C P$.

\subsection{Career plateau, work-related depression and emotional exhaustion}

According to Bardwick (1986), employees experiencing plateau have repeatedly been disregarded and ignored by the organization. This is a signal to these employees that the company doesn't respect or appreciate their real value. As a shock to many employees, $\mathrm{CP}$ has been mentioned to be a potential work stressor for many years (Blau, 1978). As stated by Fernandez, (1995) CP causes a negative cognitive evaluation of one's career and fosters levels of career-development stress.

Plateaued employees remark a lack of support from their organization. Accordingly, when employees are plateaued, they get an unfavorable message that the organization is not recognizing or supporting their efforts (Yang et al., 2018)

CPed individuals repeatedly reported unfavorable emotional and work outcomes (Yang et al., 2018). It is found to upsurge turnover intention (Heilmann et al., 2008), psychological distress (Hurst et al., 2012), discomfort (Lee, 2003), and EE (Wang et al., 2014). Correspondingly, CP has the potential to diminish ones' level of job satisfaction, motivation, and performance (Beheshtifar and Modaber, 2013).

JD-R model has been widely used to elucidate how employees' working situations affect their wellbeing and job outcomes (Bakker and Demerouti, 2007; Llorens et al., 2006). As discussed earlier, drawing upon the health impairment approach of the JD-R model, it is debated that the existence of job demands (CP) elevate strain (e.g. EE and WRD). These would ultimately explain that plateaued employees feel ignored by their organizations and this boosts their feeling of EE and depression. Consequently, we propose:

H2: $C P$ is significantly related to (a) WRD and (b) EE.

\subsection{Mediation effect}

A vast review of the literature reveals inconsistent results of the impact of HSs on numerous outcomes (e.g. Babakus et al., 2017; Geng et al., 2014). In a similar appraoch, Olugbade and Karatepe, (2019) debated that work engagement acts as a mediator in the relationship between HSs, performance, and quitting intentions. 


\section{H. P. Safavi - M. Bouzari - T. Foroutan 13/1 (2021) 83-99}

EE is considered to be a special kind of psychological and physical state of reduction. As a persistent form of strain resulting from long-term processes (Schaufeli and Enzmann 1988), EE denotes to the impression of being exhausted and emotionally devastated by one's work, manifested in the from of physical fatigue and sense of psychologically and emotionally overextended (Demerouti et al. 2001; Maslach and Leiter 2008). EE is a response to excessive job demands. Therefore, excessive job demands heighten employees' EE (Karatepe, 2013; Lee and Ashforth, 1996; Fried et al., 2008). This means, when employees try to handle the challenges related to RC and RA, they feel emotionally exhausted (Janssen et al., 1999).

Besides, employees who faced more job stressors are more disposed to sense depressing symptoms (Donald et al., 2005; Tsutsumi et al., 2001; Fried et al., 2008). Previous research consistently supported this notion and connected stressors to depression and other psychological disorders (e.g., Lambert et al., 2007; Tytherleigh et al., 2007).

According to the principle of the health impairment process of JD-R, HSs (job demands) and CP boost one's level of stress and negatively affect employees' wellbeing (Bakker and Demerouti, 2007; Llorens et al., 2006). Hence, cause EE and depression.

Expending on the JD-R model, the current study suggests that $\mathrm{CP}$ acts as a mediator through which HSs affect employees' EE and WRD. Therefore, the more individuals are opposed to a demanding job (HSs), the less they are likely to perceive an opportunity for future personal growth and accomplishments in their jobs, thus leading to a higher level of CP. Such employees, in turn, become more emotionally exhausted and depressed.

Accordingly, we propose:

H3 (a): CP mediates the relation between HSs and WRD.

$H 3$ (b): $C P$ mediates the relation between HSs and EE.

\section{METHODOLOGY}

The study proposes that HSs have an impact on CP and CP is significantly related to WRD and EE. Moreover, current study suggests the mediation impact of $C P$ in the relation between HSs namely RC and RA, and WRD and EE.

\subsection{Method}

Data was collected from flight attendants in public and private airlines in Iran via their direct supervisors through judgmental sampling technique. The team communicated with managers and explained and clarified the main aim of the study through email. A sample of the questionnaires was also sent to the management.

As proposed by Podsakoff et al. (2012), this study applied procedural and statistical remedies to control common method variance. To minimize the threat of common bias, a temporal separation was applied between predictor, mediator, and criterion variables (a week time lag in three different phases). The time I questionnaires includes information about HSs namely RC and RA and respondents' demographic characteristics. Time II questionnaires measured CP and WRD and EE were both assessed in time III. As another procedural remedy, this study focused on protecting respondents' anonymity and tried to reduce evaluation apprehension and lessen social desirability, and guaranteed them that there were no right or wrong responses. Then respondents were asked to give back all questionnaires in sealed envelopes and put them in special boxes provided for this purpose (Safavi and Bouzari, 2019). Moreover, to match the questionnaires, an identification number was given to all flight attendants and they were asked to write their number on the questionnaires.

The researchers distributed 250 questionnaires in Time I, 242 questionnaires in Time II, and 210 questionnaires in Time III. Totally, 192 questionnaires were received at the final stage. Compared to the total number of questionnaires distributed in the first phase, the research team was able to receive a total number of 192 usable questionnaires, yielding the response rate of \%77.2.

All three sets of questionnaires were subjected to the back-translation method suggested by McGorry (2000). As such, the Time I questionnaire was first prepared in English and then translated into Persian using the guidelines of the back-translation technique. This was also repeated for the Time II and Time III questions. A pilot study, comprising of 5 employees, was applied for the understandability of the items. 
The majority of the respondents were between 28 to 37 years old $(57.3 \%)$, male $(51.0 \%)$, married (50.5\%), with a bachelor's degree $(52.1 \%)$ and $34.1 \%$ have a tenure of one to five years.

\subsection{Measurements}

RC and RA items were from Rizzo et al. (1970). CP was taken from Milliman (1992). WRD was taken from Radloff (1977) and EE was taken from Maslach and Jackson (1981). This study used different Likert scales to minimize common method bias. RC and RA were measured through a 7-point Likert scale; whereas responses to items related to $\mathrm{CP}, \mathrm{WRD}$, and $\mathrm{EE}$ variables were elicited on five-point scales. The reverse code technique has been applied for reverse items.

\section{DATA ANALYSIS}

A two-step approach (Anderson and Gerbing, 1988) was applied for data analysis which included construct validity (Anderson and Gerbing, 1988; Fornell and Larcker, 1981) and composite reliability (Bagozzi and Yi, 1988). Structural equation modeling via LISREL 8.30 (Joreskog and Sorbom, 1996) was applied to investigate potential relationships.

The eigenvalue of the constructs was higher than 1.0. Five factors jointly elucidated for $91.06 \%$ of the variance. In addition to that, KMO measure as an indicator of sampling adequacy was 0.941 . Bartlett's test of sphericity was 11626.504. The results did not reveal any issues with multicollinearity.

The results of confirmatory factor analysis demonstrated that two items from RC, one item from RA, jobcontent plateau and hieratical plateau control, seven items from WRD, and three items from EE have t-value below two. Therefore, these items have been eliminated.

As represented in Table $\mathrm{I}$, the results show an amenable fit $\left(\chi^{2}=847.95, \mathrm{df}=688, \chi^{2} / \mathrm{df}=1.071, \mathrm{NFI}=0.96, \mathrm{CFI}=\right.$ $0.99, \mathrm{IFI}=0.99, \mathrm{RMR}=0.28, \mathrm{GFI}=0.81, \mathrm{AGFI}=0.79, \mathrm{PGFI}=0.72$. RMSEA $=0.035)$. The average variances extracted known as AVE were greater than 0.50 for each construct.

The shared variances (Ф2) were lower than the AVE. Therefore based on Fornell and Larcker's (1981) criterion, there was evidence for discriminant validity.

Coefficient alphas were more than the accepted level (0.70). Hence, all measures were reliable (Bagozzi and $\mathrm{Yi}, 1988)$. Altogether, the findings specified the convergent validity of the measurement model. Composite reliability of the constructs was also greater than the conventional and acceptable range (0.60).

Table I: Confirmatory Factor Analysis Results

\begin{tabular}{lcccc}
\hline Items & SD & t-value & AVE & CR \\
\hline Role conflict & & & 0.87 & 0.96 \\
1. I have to do things that should be done differently & 0.95 & 17.65 & & \\
2. I receive an assignment without the manpower to complete it. & 0.96 & 17.98 & \\
3. I have to buck a rule or policy in order to carry out an assignment. & - & - & \\
4. I work with two or more groups who operate quite differently. & 0.95 & 17.78 & \\
5. I receive incompatible requests from two or more people. & 0.94 & 17.39 & \\
6. I do things that are apt to be accepted by one person and not & 0.94 & 17.44 & \\
accepted by others. & & & \\
7. I receive an assignment without adequate resources and materials & - & - & - & - \\
to execute it. & - & - & - & - \\
8. I work on unnecessary things & & & 0.88 & 0.97 \\
Role ambiguity & 0.94 & 17.31 & & \\
1. I feel certain about how much authority I have. (reversed) & 0.94 & 17.49 & & \\
2. I have clear, planned goals and objectives for my job. (reversed) & 0.94 & 17.37 & \\
3. I know that I have divided my time properly. (reversed) & 0.95 & 17.76 & & \\
4. I know what my responsibilities are. (reversed) & 0.94 & 17.53 & & \\
5. I know exactly what is expected of me. (reversed) & - & - & & \\
6. Explanation is clear of what has to be done. (reversed) & & & 0.89 & 0.97 \\
Career plateau - Hierarchical plateau & 0.94 & 17.43 & & \\
1. My opportunities for upward movement are limited in my & & &
\end{tabular}


2. I expect to be promoted frequently in the future in my company (reversed)

3. I have reached a point where I do not expect to move much higher in my company

4. The likelihood that I will get ahead in my organization is limited

5. I am unlikely to obtain a much higher job title in my organization

6. I expect to advance to a higher level in the near future in my company (reversed)

$0.95 \quad 17.62$

\section{Career plateau - Job content plateau}

1. I expect to be constantly challenged in my job in the future (reversed)

2. I will learn and grow a lot in my job (reversed)

3. My job task $s$ and activities will become routine for me in the future

4. My job responsibilities will increase significantly in the future (reversed)

$0.94 \quad 17.31$

5. My job will continually require me to extend my abilities and knowledge (reversed)

6. I will be challenged in my job ( reversed)

\section{Work-related depression}

$0.94 \quad 17.46$

$0.94 \quad 17.34$

1. I was bothered by things that usually don't bother me.

2. I did not feel like eating; my appetite was poor.

3. I felt that I could not shake off the blues even with help from my family or friends.

4. I felt that I was just as good as other people. (reversed)

$0.95+17.59$

5. I had trouble keeping my mind on what I was doing.

6. I felt depressed.

- $\quad$ -

7. I felt that everything I did was an effort.

8. I felt hopeful about the future. (reversed)

9. I thought my life had been a failure.

10. I felt fearful.

11. My sleep was restless.

- $\quad-$

12. I was happy. (reversed)

13. I talked less than usual. (reversed)

14. I felt lonely.

15. People were unfriendly.

16. I enjoyed life. (reversed)

17. I had crying spells.

$0.95 \quad 17.56$

18. I felt sad.

$0.95 \quad 17.86$

19. I felt that people dislike me.

$0.95 \quad 17.43$

20. I could not get "going."

\section{Emotional exhaustion}

1. I feel emotionally drained from my work.

2. I feel used up at the end of the workday.

3. I feel fatigued when I get up in the morning and have to face another day on the job.

4. Working with people all day is really a strain for me.

5. I feel burned out from my work.

6. I feel frustrated by my job.

$0.94 \quad 17.28$

7. I feel I am working too hard on my job.

$0.94 \quad 17.32$

8. I feel like I am at the end of my rope.

$\chi^{2}=693.78, \mathrm{df}=650, \chi^{2} / d f=1.067, \mathrm{NFI}=0.97, \mathrm{GFI}=0.84, \mathrm{SRMR}=0.026, \mathrm{RMSEA}=0.019$

Notes: All loadings are significant at the .01 level. SD = Standardized loading

(-) Dropped during confirmatory factor analysis. 


\section{H. P. Safavi - M. Bouzari - T. Foroutan 13/1 (2021) 83-99}

Table II offers information study correlation. The results disclosed that RC was significantly correlated with RA $\left(0.283^{*}\right)$, job-content plateau $\left(0.200^{*}\right)$, hierarchical plateau $\left(0.216^{*}\right)$ WRD $\left(0.222^{* *}\right)$ and EE $\left(0.240^{* *}\right)$. RA was significantly correlated with job-content plateau $\left(0.284^{*}\right)$, hierarchical plateau $\left(0.205^{* *}\right)$ WRD $\left(0.292^{*}\right)$ and EE $\left(0.244^{* *}\right)$. Job-content plateau was correlated with hierarchical plateau $\left(0.207^{*}\right)$, WRD $\left(0.250^{*}\right)$, EE $\left(0.216^{*}\right)$. The hierarchical plateau was significantly correlated with WRD $\left(0.243^{*}\right)$ and EE $\left(0.252^{* *}\right)$. WRD was correlated with EE $\left(0.217^{* *}\right)$.

Table II: Means, standard deviations, and correlations of observed variables

\begin{tabular}{|c|c|c|c|c|c|c|c|}
\hline \multicolumn{2}{|c|}{ Variables } & 1 & 2 & 3 & 4 & 5 & 6 \\
\hline 1. & $\mathrm{RC}$ & - & & & & & \\
\hline 2. & RA & $0.283^{*}$ & - & & & & \\
\hline 3. & Job content plateau & $0.200^{*}$ & $0.284^{*}$ & - & & & \\
\hline 4. & Hierarchical plateau & $0.216^{*}$ & $0.205^{* *}$ & $0.207^{*}$ & - & & \\
\hline 5. & WRD & $0.222^{* *}$ & $0.292^{*}$ & $0.250^{*}$ & $0.243^{*}$ & - & \\
\hline 6. & $\mathrm{EE}$ & $0.240^{* *}$ & $0.244^{* *}$ & $0.216^{*}$ & $0.252^{* *}$ & $0.217^{* *}$ & - \\
\hline \multicolumn{2}{|c|}{ Mean } & 4.57 & 4.58 & 4.58 & 4.59 & 3.56 & 3.56 \\
\hline \multicolumn{2}{|c|}{ Standard deviation } & 2.12 & 2.10 & 2.14 & 2.13 & 1.42 & 1.41 \\
\hline \multicolumn{2}{|c|}{ Cronbach's alpha } & 0.97 & 0.97 & 0.97 & 0.97 & 0.99 & 0.97 \\
\hline
\end{tabular}

Note: Composite score was computed for each variable. ${ }^{*} \mathrm{p}<0.05,{ }^{* * *} \mathrm{p}<0.01$ (two-tailed test).

\subsection{Hypotheses testing}

Normality of data were checked via skewness test. As offered by Kline (2011), the skewness values were lower than 3.00. The results evidently proved the data normality.

The second phase involves testing the proposed hypotheses via structural equation modeling (Joreskog and Sorbom, 1996). As presented in Figure I and Table III, the hypothesized model has better fit $\left(\chi^{2}=211.58, d f=206\right.$, $\left.\chi^{2} / d f=111 ; \mathrm{NFI}=0.98, \mathrm{GFI}=0.91, \mathrm{RMSEA}=0.0012\right)$. The results confirmed the significant association between HSs and CP $\left(\beta_{21}=0.93, t=4.57\right)$. Therefore, hypothesis 1 is supported. Additionally, CP is related with WRD $\left(\beta_{32}=0.51, t=4.09\right)$ and $\mathrm{EE}\left(\beta_{42}=0.48, t=0.94\right)$. Therefore hypotheses $2 \mathrm{a}$ and $2 \mathrm{~b}$ are supported. Sobel test results also supported the mediation effect $(\mathrm{H} 3 \mathrm{a}, \mathrm{b})$; that is $\mathrm{CP}$ is a mediator between HSs and WRD (z-score $=3.37)$ and EE $(z$-score $=3.38)$.

The majority of control variables do not have any significant effects on study variables. However, the results regarding the hypothesized relationships do not change with or without the control variables. The current study applied bootstrapping to approve the mediation impact (Hayes, 2013). The results of booststrapping supported the aforementioned results.

Table III: Results of model comparison (Full mediation and Partial Mediation)

1. Hypothesized model (Full mediation)

$\chi^{2} \quad d f \quad \Delta \chi^{2} \quad \Delta d f$

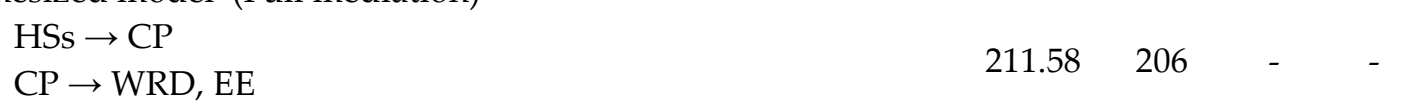

2. Alternative model I (Partial mediation)

$$
\begin{aligned}
& \text { HSs } \rightarrow \text { CP } \\
& \text { HSs } \rightarrow \text { WRD, EE } \\
& \mathrm{CP} \rightarrow \text { WRD, EE }
\end{aligned}
$$

The hypothesized model appears to yield a better fit to the data than alternative models 


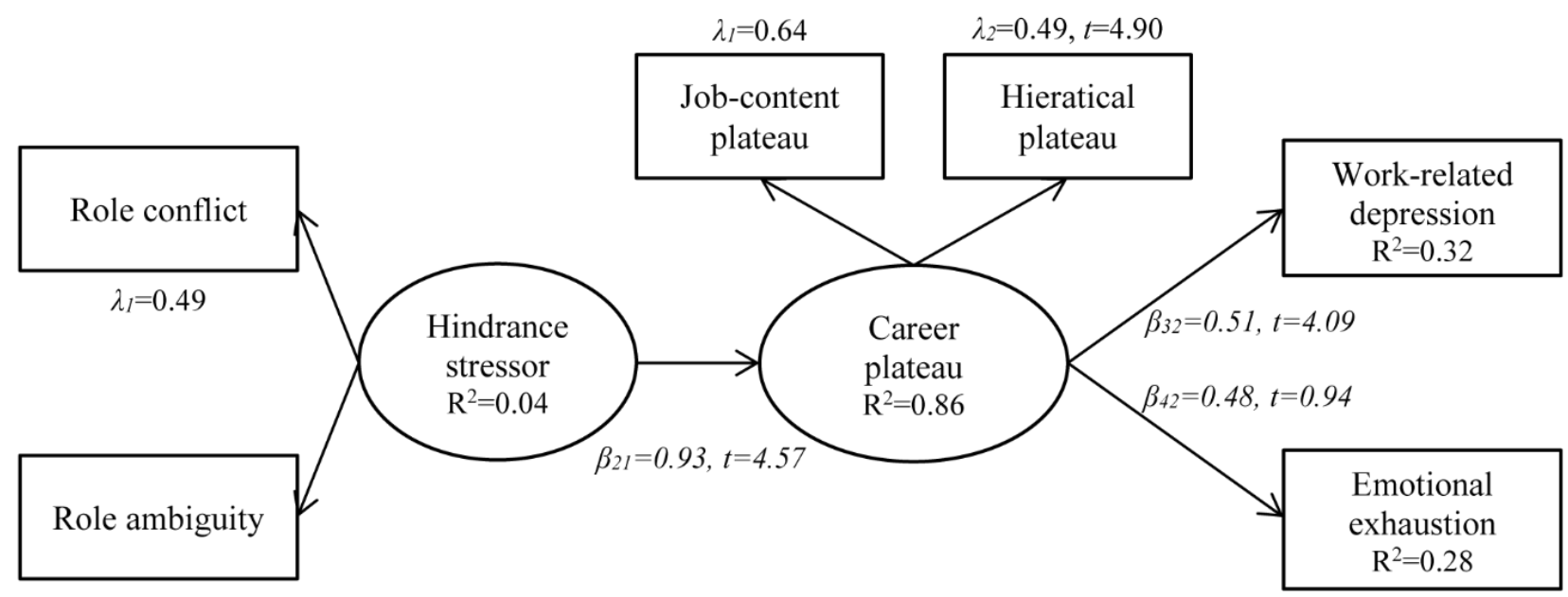

$\lambda_{2}=0.52, t=5.43$

Figure I: Structural model test results

Model fit statistics:

$\chi^{2}=211.58, d f=206, \chi^{2} / d f=111 ; N F I=0.98, G F I=0.91, R M S E A=0.0012$

$\begin{array}{ll}\mathrm{HSs} \rightarrow \mathrm{CP} \rightarrow \mathrm{WRD} & 3.37 \\ \mathrm{HSs} \rightarrow \mathrm{CP} \rightarrow \mathrm{EE} & 3.38\end{array}$

$z$-score

Note: T-values are shown in parentheses except for the loading of concern that was initially fixed to 1.00 to set the metric for the underlying career adaptability variable.

Table IV: Bias-Correlated Bootstrapping Results

Hypothesized mediating relationship $\quad$ Indirect effect $\quad$ LLCI $\quad$ ULCI

$\begin{array}{llll}\mathrm{HSs} \rightarrow \mathrm{CP} \rightarrow \mathrm{WRD} & 0.091 & 0.027 & 0.165 \\ \mathrm{HSs} \rightarrow \mathrm{CP} \rightarrow \mathrm{EE} & 0.086 & 0.010 & 0.139\end{array}$

Note: Bias-Correlated Bootstrapping analysis was made with a bootstrapped 5.000 sample at $95 \%$ confidence interval.

\section{DISCUSSION}

\subsection{Evaluation of findings and theoretical implications}

This empirical investigation inspected the effects of HSs manifested by RA and RC on CP. This examination provides additional insights regarding the nature of impacts of HSs on CP. Moreover, the present study connects HSs on two negative job-related outcomes namely EE and WRD through CP from cabin crews applying time-lag design in Iran. Inspecting the mediation impacts of $\mathrm{CP}$ in this relation seems noteworthy since it has been largely overlooked in the relevant service literature.

The results showed that HSs enhance CP suggest that employees who experience HSs in the form of RA and RCs are more probable to view and consider these HSs as a possible threat to their personal progress and thus have a perception of CP. The result is in line with the percepts of the JD-R model (Bakker and Demerouti, 2007). Moreover, in line with the percepts of the JD-R model (Bakker and Demerouti, 2007), it is contended 


\section{H. P. Safavi - M. Bouzari - T. Foroutan 13/1 (2021) 83-99}

that the existence of $\mathrm{CP}$ elevates strain. To put it differently, plateaued employees feel ignored by their organizations, and this boosts their feeling of EE and depression.

The result that $\mathrm{CP}$ fully mediates the effects of HSs on EE and WRD suggests that employees who experience HSs would experience a plateau at work and they rarely perceive an opportunity for future personal growth and accomplishments in their jobs. These plateaued employees, in turn, become more emotionally exhausted and depressed.

It should be acknowledged that since a review of the literature reveals inconsistent findings of the effects of HSs on various consequences (Geng et al., 2014; Olugbade and Karatepe, 2019), HSs would not always cause employees' CP or other negative outcomes. Employees who work in different hospitality settings or cultural settings would have different perceptions towards HSs.

\subsection{Practical Implication}

In the present research, job demands and resources were discussed from the perspective of the JD-R model. For that reason, the model examined the associations between HSs, CP, EE, and WRD.

Therefore, it is discussed that job demands can cause employees to feel anxious and stressed. This can suppress employees' perceptions of their future progress and development and eventually cause a higher level of CP. As a consequence, employees who deal with HSs are more likely to perceive these stressors as a potential obstacle for their individual growth and CP. Additionally, employing the JD-R model, we argued that the existence of $\mathrm{CP}$ as a job demand can adversely affect employees' well-being and boost their EE and WRD.

Specifically, this study discovered that employees' EE and WRD are more expected to happen when their appreciation of $\mathrm{CP}$ is triggered by their perception of HSs (i.e., RC and RA).

Our findings delineate several implications for both personnel and managers in the airline industry. To start with, the current study pointed out that the level of $\mathrm{CP}$ heightened when cabin crew members suffer from a high level of RA and RC (job demands). Specifically, employees (crew members) which work in a situation and setting where there are lots of RC and RA, are more likely to perceive that these stressors impede their future job achievements and personal growth (Fong et al., 2018). Considering this finding, the management of airline organizations should try to minimize the extent to which employees can confront with such demands and stressors. For this reason, they should take notice of RA and RC and try to create an environment where these crew members are not repeatedly faced with RA and RC.

However, since there is always a disparity between employees' perceived role and management's expected role, RA and RC are unavoidable. Therefore, managers should try to cope with these complexities and uncertainties in the environment. This necessitates them to avoid ambiguity in the environment (Lane and Klenke, 2004).

They can remove/ reduce sources of RA as a job demand through job design, active training and mentoring, and performance feedback, correspondingly (Lin et al., 2018). Therefore, consistent with Lin and Ling (2018) we suggest airline managers helping crew members in understanding their role responsibilities and expectations through establishing a clear job description consisting of clear responsibilities, tasks, and goals when designing their jobs.

In addition, providing active training to crew members based on actual role expectations and requirements is a sign that management care about employees. This eventually can shape the perception of an environment with the possibility of growth and future achievements for employees (Olugbade and Karatepe, 2019). Thus, organizing mentoring and preparation programs by managers can considerably reduce these sources of job demands and work stressors. Mentors not only should clarify the organization's expectations from crew members, but also help employees in understanding their roles, tasks, and performance standards through direct coaching behaviors (Lankau and Scandura, 2002).

Furthermore, as Lin et al., (2018) stated, in unpredictable environments, frontline employees (i.e., crew members) should respond quickly to passengers' different needs and requests. Hence, airline companies can use training programs that point out the best ways through which crew members can respond to passengers' requests punctually. They can teach crew members how to deal with different demands coming from various passengers, even when their requests are inconsistent with those that companies set. 


\section{H. P. Safavi - M. Bouzari - T. Foroutan 13/1 (2021) 83-99}

Moreover, airline firms should establish clear performance criteria and clear promotional opportunities for their crew members. They also have to provide regular feedback to crew members based on their actual performances (Lin et al., 2018). These clarities and transparencies can remove/lessen the sources of job demands and eventually minimize their negative outcomes.

Besides, since unpredictable needs and ambiguous conditions can affect the service quality and performance of the employees, our suggestion to both managers and crew members is to increase their tolerance for ambiguity in order to adapt to an unpredictable and uncertain situation (McLain et al., 2015).

Second, as per previous works (e.g., Bardwick, 1986; Yang et al., 2018; Yang et al., 2019) our findings show plateaued individuals regularly feel that they have been ignored and neglected by the organization. This signals to these employees that company doesn't respect or appreciate their value. Such factors (i.e., job demands) have the potentiality to deteriorate employees' psychological well-being (Bardwick, 1986). Likewise, our findings reveal that $\mathrm{CP}$ and lack of career promotional opportunities would cause negative job outcomes such as EE and workplace depression among crew members. Therefore, managers of these companies should take proactive approaches to decrease these job demands and deal with plateaued employees. They also should put enough effort into changing these employees' perceptions and negative attitudes toward their job (Yang et al., 2018). For instance, well-designed and transparent organizational policies in combination with job transfers and communication and training sessions can be used to reduce the negative impacts of CP. Accordingly, managers should design the work environments in a way that employees have the chance and opportunity for future growth and promotion. They can manage this by offering additional responsibilities to them through job enlargement, job rotation (Yang et al., 2018), and job transfers (Rotondo and Perrewé, 2000). Nevertheless, HR practitioners should avoid making unrealistic promises about future job promotions starting from the recruitment stage and continuing in the following career stages (Tekleab and Taylor, 2003; Zhao et al., 2007).

$\mathrm{CP}$ suggests that employees have some unmet expectations which can explain the negative outcome of CP. Thus, organizations need to understand employees' expectations about their jobs (Yang et al., 2018). Consequently, managers and mentors should regularly communicate with employees to lessen the existing discrepancy in expectations of each other (Tekleab and Taylor, 2003; Zhao et al., 2007). In addition, consistent with Bardwick, (1986), we highly suggest managers providing honest and straightforward appraisal and give clear feedback, ways to reduce the gap between managers' evaluation and employees' expectations.

Furthermore, if airline companies desire their crew members to perceive the existence of an opportunity for future learning and growth in their jobs, they should organize a series of training programs that can foster such perceptions. Dreher and Ash (1990) debated that employees who had more mentoring sessions, got more promotions, greater income, and a higher level of satisfaction from their pay and benefits than staffs with less mentoring experiences. Hence, in accordance with other works that address the connection between mentoring and CP (e.g., Chao, 1990; Greenhaus et al., 2008), we recommend managers establish adequate mentoring programs for crew members. By this, mentors can impart a sense of self-identity in employees and familiarize them with the organizational culture which enables them to place their trust in the organization (Lin et al., 2018).

Last but not least, airline management can provide job security to those crew members with a good level of performance. These circumstances can prevent employees to experience and deteriorate from HSs.

\subsection{Limitations of the study and future research directions}

Similar to other empirical studies, this study encountered a number of limitations that could open doors for upcoming work. To start with, this study used CP as the mediator of the study relationships. Future studies may include supplementary potential mediators to illuminate the mechanism through which job-related stressors are related to EE and WRD. In addition to this, EE and WRD were considered as the outcomes in the conceptual model. Incorporating other attitudinal or performance outcomes in the model would give scholars a better insight into the impact of work-related stressors in organizations.

What is more, although this study applied a time-lag design to control common method variance, to organize more meticulous findings, future research should advantage of longitudinal research design. Finally, yet importantly, this study directed a survey in airline industries in Iran that suffers from the lack of empirical 


\section{H. P. Safavi - M. Bouzari - T. Foroutan 13/1 (2021) 83-99}

and academic research concerning the factors that could elevate mental health problems among cabin crews. Yet, this single cultural environment may increase the concern of generalizability. To extend the knowledgebased concerning the objectives of the current study, henceforth to expand the database for further generalization, the use of cross-cultural study would be highly suggested.

\section{REFERENCES}

Alam, M. A. (2016). Techno-stress and productivity: Survey evidence from the aviation industry. Journal of Air Transport Management, 50, 62-70.

Alola, U. V., Olugbade, O. A., Avci, T., \& Öztüren, A. (2019). Customer incivility and employees' outcomes in the hotel: Testing the mediating role of emotional exhaustion. Tourism Management Perspectives, 29, 917.

Anderson, J. C., \& Gerbing, D. W. (1988). Structural equation modeling in practice: A review and recommended two-step approach. Psychological Bulletin, 103(3), 411-423.

Arnold, J.; Cooper, C.L.; Robertson, I.T. Work Psychology: Understanding Human Behavior in the Workplace. (Third Edition) Harlow, England: Prentice Hall, 1998.

Baba, V. V., Galperin, B. L., \& Lituchy, T. R. (1999). Occupational mental health: A study of work-related depression among nurses in the Caribbean. International Journal of Nursing Studies, 36(2), 163-169.

Babakus, E., Yavas, U., \& Karatepe, O. M. (2017). Work engagement and turnover intentions: Correlates and customer orientation as a moderator. International Journal of Contemporary Hospitality Management, 29(6), 1580-1598.

Bagozzi, R. P., \& Yi, Y. (1988). On the evaluation of structural equation models. Journal of the Academy of Marketing Science, 16(1), 74-94.

Bakker, A. B., \& Demerouti, E. (2007). The job demands-resources model: State of the art. Journal of Managerial Psychology, 22 (3), 309-328.

Ballard, T. J., Romito, P., Lauria, L., Vigiliano, V., Caldora, M., Mazzanti, C., \& Verdecchia, A. (2006). Selfperceived health and mental health among women flight attendants. Occupational and Environmental Medicine, 63(1), 33-38.

Bardwick, J. M. (1986). The plateauing trap: How to avoid it in your career... and your life. New York: Amacom.

Bardwick, J. M. (1986). The plateauing trap: How to avoid it in your career... and your life. American Management Association.

Beheshtifar, M., \& Modaber, H. (2013). The investigation of relation between occupational stress and career plateau. Interdisciplinary Journal of Contemporary Research in Business, 4(11), 650-660.

Blau, B. (1978). Understanding mid-career stress. Management Review, 67(8),57-62.

Bowen, P., Edwards, P., Lingard, H., \& Cattell, K. (2014). Occupational stress and job demand, control and support factors among construction project consultants. International Journal of Project Management, 32(7), 1273-1284.

Cavanaugh, M. A., Boswell, W. R., Roehling, M. V., \& Boudreau, J. W. (2000). An empirical examination of self-reported work stress among US managers. Journal of Applied Psychology, 85(1), 64-74.

Chang, C. P., \& Ju-Mei, C. H. I. U. (2009). Flight attendants' emotional labor and exhaustion in the Taiwanese airline industry. Journal of Service Science and Management, 2(4), 305-311.

Chao, G. T. (1990). Exploration of the conceptualization and measurement of career plateau: A comparative analysis. Journal of Management, 16(1), 181-193. 


\section{H. P. Safavi - M. Bouzari - T. Foroutan 13/1 (2021) 83-99}

Chen, C. F., \& Kao, Y. L. (2011). The antecedents and consequences of job stress of flight attendants-Evidence from Taiwan. Journal of Air Transport Management, 17(4), 253-255.

Chen, K. Y., Chang, C. W., \& Wang, C. H. (2019). Frontline employees' passion and emotional exhaustion: the mediating role of emotional labor strategies. International Journal of Hospitality Management, 76, 163-172.

Chen, S. C. (2017). Paternalistic leadership and cabin crews' upward safety communication: The motivation of voice behavior. Journal of Air Transport Management, 62, 44-53.

Choi, K. S., \& Kang, S. K. (2010). Occupational psychiatric disorders in Korea. Journal of Korean medical science, 25(Suppl), S87-S93.

Crawford, E. R., LePine, J. A., \& Rich, B. L. (2010). Linking job demands and resources to employee engagement and burnout: a theoretical extension and meta-analytic test. Journal of Applied Psychology, 95(5), 834-848.

Cynkar, A. (2007). Whole workplace health. Monitor on Psychology, 38, 28-31.

Demerouti E, AB Bakker, F Nachreiner and W Schaufeli (2001) The job demands-resources model of burnout. Journal of Applied Psychology 86(3), 499-512.

Donald, I., Taylor, P., Johnson, S., Cooper, C., Cartwright, S., \& Robertson, S. (2005). Work environments, stress, and productivity: An examination using ASSET. International Journal of Stress Management, 12(4), 409-423.

Dreher, G. F., \& Ash, R. A. (1990). A comparative study of mentoring among men and women in managerial, professional, and technical positions. Journal of applied psychology, 75(5), 539-546

Feijo, D., Luiz, R. R., \& Camara, V. M. (2014). Common mental disorders among civil aviation flight attendants. Aviation, Space, and Environmental Medicine, 85(4), 433-439.

Feldman, D. C., \& Weitz, B. A. (1988). Career plateaus reconsidered. Journal of Management, 14, 69-80.

Ference, T. P., Stoner, J. A. F., \& Warren, E. K. (1977). Managing the career plateau. Academy of Management Review, 2, 602-612.

Ference, T. P., Stoner, J. A. F., \& Warren, E. K. (1977). Managing the career plateau. Academy of Management Review, 2(4), 602-612.

Fong, L. H. N., Chui, P. M. W., Cheong, I. S. C., \& Fong, D. K. C. (2018). Moderating effects of social support on job stress and turnover intentions. Journal of Hospitality Marketing \& Management, 27(7), 795-810.

Fornell, C., \& Larcker, D. F. (1981). Evaluating structural equation models with unobservable variables and measurement error. Journal of Marketing Research, 18(1), 39-50.

Fortes-Ferreira, L., Peiró, J.M., González-Morales, M.G., Martín, I., 2006. Work-related stress and well-being: the roles of direct action coping. Scandinavian Journal of Psychology, 47(4), 293-302.

French, K. A., Allen, T. D., \& Henderson, T. G. (2019). Challenge and hindrance stressors in relation to sleep. Social Science \& Medicine, 222, 145-153.

Fried, Y., Shirom, A., Gilboa, S., \& Cooper, C. L. (2008). The mediating effects of job satisfaction and propensity to leave on role stress-job performance relationships: Combining meta-analysis and structural equation modeling. International Journal of Stress Management, 15(4), 305-328.

Geng, Z., Liu, C., Liu, X., \& Feng, J. (2014). The effects of emotional labor on frontline employee creativity. International Journal of Contemporary Hospitality Management, 26(7), 1046-1064.

Geng, Z., Liu, C., Liu, X., \& Feng, J., (2014) "The effects of emotional labor on frontline employee creativity", International Journal of Contemporary Hospitality Management, 26(7), 1046-1064.

Greenhaus, J. H., Callanan, G. A., \& DiRenzo, M. (2008). A boundaryless perspective on careers. Handbook of Organizational Behavior, 1, 277-299. 


\section{H. P. Safavi - M. Bouzari - T. Foroutan 13/1 (2021) 83-99}

Hayes, A. F. (2013). Introduction to mediation, moderation, and conditional process analysis: A regression-based approach. New York: Guilford Press.

Heilmann, S. G., Holt, D. T., \& Rilovick, C. Y. (2008). Effects of career plateauing on turnover: A test of a model. Journal of Leadership \& Organizational Studies, 15(1), 59-68.

Hurst, C. S., Kungu, K., \& Flott, P. (2012). Stress, organizational citizenship behaviors, and coping: Comparisons among plateaued and non-plateaued employees. Business and Management Research, 1, $17-27$.

Janssen, P.P.M., Schaufeli, W.B. and Houkes, I. (1999), “Work-related and individual determinants of the three burnout dimensions", Work and Stress, 13(1), 74-86.

Jex, S. M., Crossley C.D., (2005). Organizational consequences. In Barling J, Kelloway EK.

Joreskog, K., \& Sorbom, D. (1996). LISREL 8: User's Reference Guide. Chicago: Scientific Software International, Inc.

Jou, R. C., Kuo, C. W., \& Tang, M. L. (2013). A study of job stress and turnover tendency among air traffic controllers: The mediating effects of job satisfaction. Transportation Research Part E: Logistics and Transportation Review, 57, 95-104.

Karatepe, O. M. (2013). The effects of work overload and work-family conflict on job embeddedness and job performance. International Journal of Contemporary Hospitality Management. 25(4), 614-634.

Karatepe, O. M., \& Choubtarash, H. (2014). The effects of perceived crowding, emotional dissonance, and emotional exhaustion on critical job outcomes: A study of ground staff in the airline industry. Journal of Air Transport Management, 40, 182-191.

Karatepe, O. M., \& Ehsani, E. (2012). Work-related depression in frontline service jobs in the hospitality industry: Evidence from Iran. Journal of Human Resources in Hospitality \& Tourism, 11(1), 16-35.

Karatepe, O. M., \& Kim, T. T. (2020). Investigating the selected consequences of boreout among cabin crew. Journal of Air Transport Management, 82, 101739.

Karatepe, O. M., \& Shahriari, S. (2014). Job embeddedness as a moderator of the impact of organisational justice on turnover intentions: A study in Iran. International Journal of Tourism Research, 16(1), 22-32.

Katz, D., \& Kahn, R. L. (1978). The social psychology of organizations (2nd ed.). New York, NY: John Wiley \& Sons.

Kline, R. B. (2011). Principles and Practice of Structural Equation Modeling, $3^{\text {rd }}$ ed. New York, NY: The Guilford Press.

Ko, S. H. (2018). A Study on the Structural Relationship between Role Stress and Creative Self-Efficacy and Creativity among Flight Attendants. International Journal of Pure and Applied Mathematics, 118(24).

Kuhn, R. (1988). Psychological tests reduce counterproductive acts by employees. Assets Protection, 9, 9-12.

Lambert, E. G., Hogan, N. L., Dial, K. C., Altheimer, I., \& Barton-bellessa, S. M. (2012). Examining the effects of stressors on organizational citizenship behaviors among private correctional staff: A preliminary study. Security Journal, 25(2), 152-172.

Lambert, V.A., Lambert, C.E., Petrini, M., \& Li, X.M. (2007). Predictors of physical and mental health in hospital nurses within the People's Republic of China. International nursing review, 54(1), 85-91.

Lane, M. S., \& Klenke, K. (2004). The ambiguity tolerance interface: A modified social cognitive model for leading under uncertainty. Journal of Leadership E Organizational Studies, 10(3), 69-81.

Lankau, M. J., \& Scandura, T. A. (2002). An investigation of personal learning in mentoring relationships: Content, antecedents, and consequences. Academy of Management Journal, 45(4), 779-790. 


\section{H. P. Safavi - M. Bouzari - T. Foroutan 13/1 (2021) 83-99}

Lapalme, M. È., Tremblay, M., \& Simard, G. (2009). The relationship between career plateauing, employee commitment and psychological distress: The role of organizational and supervisor support. The International Journal of Human Resource Management, 20(5), 1132-1145.

Lazarus, R. S. (1993). From psychological stress to the emotions: A history of changing outlooks. Annual Review of Psychology, 44, 1-21

Lee, J. S., Joo, E. J., \& Choi, K. S. (2013). Perceived stress and self-esteem mediate the effects of work-related stress on depression. Stress and Health, 29(1), 75-81.

Lee, P. C. B. (2003). Going beyond career plateau: Using professional plateau to account for work outcomes. Journal of Management Development, 22(6), 538-551.

Lee, R.T., \& Ashforth, B.E. (1996). A meta-analytic examination of the correlates of the three dimensions of job burnout. Journal of Applied Psychology, 81(2), 123-133.

Lee, S., \& Kim, J. K. (2018). Factors contributing to the risk of airline pilot fatigue. Journal of Air Transport Management, 67, 197-207.

LePine, J. A., Podsakoff, N. P., \& LePine, M. A. (2005). A meta-analytic test of the challenge stressor hindrance stressor framework: An explanation for inconsistent relationships among stressors and performance. Academy of Management Journal, 48(5), 764-775.

Li, X., Sanders, K., \& Frenkel, S. (2012). How leader-member exchange, work engagement and HRM consistency explain Chinese luxury hotel employees' job performance. International Journal of Hospitality Management, 31(4), 1059-1066.

Lin, M., \& Ling, Q. (2018). Is role stress always harmful? Differentiating role overload and role ambiguity in the challenge-hindrance stressors framework. Tourism Management, 68, 355-366.

Lin, Y. C., Chen, A. S. Y., \& Lai, Y. T. (2018). Breach or bridge your career? Understanding the relationship between career plateau and internal employability. Personnel Review, 47(5), 986-1002.

Llorens, S., Bakker, A.B., Schaufeli, W. and Salanova, M. (2006), “Testing the robustness of the job demandsresources model", International Journal of Stress Management, 13(3). 378-391.

Lv, Q., Xu, S., \& Ji, H. (2012). Emotional labor strategies, emotional exhaustion, and turnover intention: An empirical study of Chinese hotel employees. Journal of Human Resources in Hospitality \& Tourism, 11(2), 87-105.

Maslach, C., \& Jackson, S. E. (1981). The measurement of experienced burnout. Journal of Organizational Behavior, 2(2), 99-113.

Maslach, C., \& Leiter, M. P. (2008). Early predictors of job burnout and engagement. Journal Of Applied Psychology, 93(3), 498-512.

McGorry, S. Y. (2000). Measurement in a cross-cultural environment: survey translation issues. Qualitative Market Research: An International Journal, 3(2), 74-81.

McLain, D. L., Kefallonitis, E., \& Armani, K. (2015). Ambiguity tolerance in organizations: Definitional clarification and perspectives on future research. Frontiers in Psychology, 6, 1-7.

Milliman, J. F. (1992). Causes, consequences, and moderating factors of career plateauing. Unpublished doctoral dissertation, University of Southern California, Los Angeles.

Montgomery, A., Spânu, F., Bəban, A., \& Panagopoulou, E. (2015). Job demands, burnout, and engagement among nurses: A multi-level analysis of ORCAB data investigating the moderating effect of teamwork. Burnout Research, 2(2-3), 71-79.

Morakabati, Y. (2011). Deterrents to tourism development in Iran. International Journal of Tourism Research, 13(2), 103-123. 
O'neill, J. W., \& Davis, K. (2011). Work stress and well-being in the hotel industry. International Journal $f$ Hospitality Management, 30(2), 385-390.

Office of Applied Studies. (2007). Depression among adults employed full-time, by occupational category. The NSDUH Report. Washington, DC: U.S. Department of Health and Human Services.

Öge, E., Cetin, M., \& Top, S. (2018). The effects of paternalistic leadership on workplace loneliness, work family conflict and work engagement among air traffic controllers in Turkey. Journal of Air Transport Management, 66, 25-35.

Olugbade, O. A., \& Karatepe, O. M. (2019). Stressors, work engagement and their effects on hotel employee outcomes. The Service Industries Journal, 39(3-4), 279-298.

Ortqvist, D., \& Wincent, J. (2006). Prominent consequences of role stress: A meta-analytic review. International Journal of Stress Management, 13(4), 399-422.

Ozer, M., Chang, C. H. D., \& Schaubroeck, J. M. (2014). Contextual moderators of the relationship between organisational citizenship behaviours and challenge and hindrance stress. Journal of Occupational and Organizational Psychology, 87(3), 557-578.

Podsakoff, N. P., LePine, J. A., \& LePine, M. A. (2007). Differential challenge stressor-hindrance stressor relationships with job attitudes, turnover intentions, turnover, and withdrawal behavior: A metaanalysis. Journal of Applied Psychology, 92(2), 438-454.

Podsakoff, P. M., MacKenzie, S. B., \& Podsakoff, N. P. (2012). Sources of method bias in social science research and recommendations on how to control it. Annual Review of Psychology, 63, 539-569.

Radloff, L. S. (1977). The CES-D scale: A self-report depression scale for research in the general population. Applied Psychological Measurement, 1(3), 385-401.

Rathi, N., \& Lee, K. (2016). Emotional exhaustion and work attitudes: Moderating effect of personality among frontline hospitality employees. Journal of Human Resources in Hospitality \& Tourism, 15(3), 231-251.

Rizzo, J. R., House, R. J., \& Lirtzman, S. I. (1970). Role conflict and ambiguity in complex organizations. Administrative Science Quarterly, 15(2), 150-163.

Rodell, J. B., \& Judge, T. A. (2009). Can "good" stressors spark "bad" behaviors? The mediating role of emotions in links of challenge and hindrance stressors with citizenship and counterproductive behaviors. Journal of Applied Psychology, 94(6), 1438.

Rotondo, D. M., \& Perrewé, P. L. (2000). Coping With a Career Plateau: An Empirical Examination of What Works and What Doesn't . Journal of Applied Social Psychology, 30(12), 2622-2646.

Safavi, H. P., \& Bouzari, M. (2019). The association of psychological capital, career adaptability and career competency among hotel frontline employees. Tourism Management Perspectives, 30, 65-74.

Salami, S. O. (2010). Career plateauing and work attitudes: Moderating effects of mentoring others with Nigerian employees. Europe's Journal of Psychology, 6(4), 71-92.

Schaufeli WB and D Enzmann (1988) The burnout companion to study and practice: a critical analysis. Taylor and Francis, London.

Shabeer, S., Mohammed, S. J., Jawahar, I. J., \& Bilal, A. R. (2019). The mediating influence of fit perceptions in the relationship between career adaptability and job content and hierarchical plateaus. Journal of Career Development, 46(3), 332-345.

Shahin, A., \& Dabestani, R. (2010). Correlation analysis of service quality gaps in a four-star hotel in Iran. International Business Research, 3(3), 40-46.

Sonnentag, S., \& Natter, E. (2004). Flight attendants' daily recovery from work: Is there no place like home? International Journal of Stress Management, 11(4), 366-391. 
Steffy, B. D., Jones, J. W., Murphy, L. R., \& Kunz, L. (1986). A demonstration of the impact of stress abatement programs on reducing employee's accidents and their costs. American Journal of Health Promotion, 1(2), 25-32.

Tekleab, A. G., \& Taylor, M. S. (2003). Aren't there two parties in an employment relationship? Antecedents and consequences of organization-employee agreement on contract obligations and violations. Journal of Organizational Behavior, 24, 585-608.

Tims, M., Bakker, A. B., \& Derks, D. (2013). The impact of job crafting on job demands, job resources, and well-being. Journal of Occupational Health Psychology, 18(2), 230-240.

Tourigny, L., Baba, V.V., \& Wang, X. (2010). Stress episode in aviation: the case of China. Cross Cultural Management: An International Journal, 17(1), 62-78.

Tsaur, S. H., \& Tang, Y. Y. (2012). Job stress and well-being of female employees in hospitality: The role of regulatory leisure coping styles. International Journal of Hospitality Management, 31(4), 1038-1044.

Tytherleigh, M. Y., Jacobs, P. A., Webb, C., Ricketts, C., \& Cooper, C. (2007). Gender, Health and Stress in English University Staff-Exposure or Vulnerability? Applied Psychology, 56(2), 267-287.

Vandevala, T., Pavey, L., Chelidoni, O., Chang, N. F., Creagh-Brown, B., \& Cox, A. (2017). Psychological rumination and recovery from work in intensive care professionals: associations with stress, burnout, depression and health. Journal of Intensive Care, 5(1), 1-8.

Vatankhah, S., Javid, E., \& Raoofi, A. (2017). Perceived organizational support as the mediator of the relationships between high-performance work practices and counter-productive work behavior: Evidence from airline industry. Journal of Air Transport Management, 59, 107-115.

Wallace, J. C., Edwards, B. D., Arnold, T., Frazier, M. L., \& Finch, D. M. (2009). Work stressors, role-based performance, and the moderating influence of organizational support. Journal of applied psychology, 94(1), 254.

Wang, Y.-H., Hu, C., Hurst, C. S., \& Yang, C.-C. (2014). Antecedents and outcomes of career plateaus: The roles of mentoring others and proactive personality. Journal of Vocational Behavior, 85(3), 319-328.

Webster, J. R., Beehr, T. A., \& Love, K. (2011). Extending the challenge-hindrance model of occupational stress: The role of appraisal. Journal of Vocational Behavior, 79(2), 505-516.

Wickramasinghe, V., \& Jayaweera, M. (2010). Impact of career plateau and supervisory support on career satisfaction: A study in offshore outsourced IT firms in Sri Lanka. Career Development International, 15(6), 544-561.

Yang, W. N., Johnson, S., \& Niven, K. (2018). “That's not what I signed up for!” A longitudinal investigation of the impact of unmet expectation and age in the relation between career plateau and job attitudes. Journal of Vocational Behavior, 107, 71-85.

Yang, W. N., Niven, K., \& Johnson, S. (2019). Career plateau: A review of 40 years of research. Journal of Vocational Behavior. 110, 286-302.

Zamani-Farahani, H., \& Henderson, J. C. (2010). Islamic tourism and managing tourism development in Islamic societies: the cases of Iran and Saudi Arabia. International journal of tourism research, 12(1), 79-89.

Zhao, H., Wayne, S. J., Glibkowski, B. C., \& Bravo, J. (2007). The impact of psychological contract breach on work-related outcomes: A meta-analysis. Personnel Psychology, 60, 647-680.

Zhong, J. I. E., You, J., Gan, Y., Zhang, Y., Lu, C., \& Wang, H. (2009). Job stress, burnout, depression symptoms, and physical health among Chinese university teachers. Psychological Reports, 105(3), 1248-1254. 